\title{
Asymmetry Assessment for Saudi Adult Male Population: Grummons Analysis
}

\author{
${ }^{1}$ Harshal Kumar, ${ }^{2}$ lbadullah Kundi, ${ }^{3}$ Mohammad K Alam
}

\section{ABSTRACT}

Objectives: The prime aim of the following study is to measure the facial parameters of the horizontal plane, mandibular morphology and linear asymmetries using Grummons analysis (GA).

Materials and methods: Standard posterior-anterior cephalogram (PAC) of 100 esthetically pleasing faces without any orthodontic treatment and craniofacial deformity were taken from the radiology archive. All radiographs are digitally analyzed for the GA. Various linear and angular variables were measured for horizontal plane, mandibular morphology, and linear asymmetries.

Results: Descriptive analysis has been done using SPSS software. Mean disparities has been calculated to check the difference between different parameters with other ethnics. GA of PAC of Saudi adult male showed variable degrees of facial asymmetry. The lower third of the face showed greater asymmetries. Mandibular deviation, maxillary midline deviations, and mandibular midline deviation are $3.51 \mathrm{~mm}, 2.52 \mathrm{~mm}$ and $2.86 \mathrm{~mm}$, respectively.

Conclusion: This study has measured PAC; horizontal plane, mandibular morphology and linear asymmetries for the Saudi adult male using GA. Facial asymmetries are found to have a common finding in Saudi adult male subjects who have normal facial harmony.

Keywords: Grummons analysis, Posterior anterior cephalogram, Saudi.

How to cite this article: Kumar $\mathrm{H}$, Kundi I, Alam MK. Asymmetry Assessment for Saudi Adult Male Population: Grummons Analysis. World J Dent 2019;10(1):46-51.

Source of support: Nil

Conflict of interest: None

\section{INTRODUCTION}

Asymmetry in the face and dentition is a naturally occurring phenomenon. In most cases, facial asymmetry can only be detected by comparing homologous parts of the face. Mild asymmetry of the facial region is a common finding in a general population and is usually without

\footnotetext{
${ }^{1}$ Department of Orthodontic, Awadh Dental College and Hospital Jamshedpur, Jharkhand, India

${ }^{2,3}$ Department of Preventive Dentistry, Orthodontic Division, College of Dentistry, Al-Jouf University, Al-Jouf, Kingdom of Saudi Arabia

Corresponding Author: Ibadullah Kundi, Department of Preventive Dentistry, Orthodontic Division, College of Dentistry, Jouf University, Al-Jouf, Kingdom of Saudi Arabia, Phone: +966542048412, e-mail: dr.ibadullah.kundi@jodent.org
}

noticeable esthetic or functional significance. Asymmetry becomes important when it affects function, esthetics or social acceptance of an individual. ${ }^{1,2}$

The etiology of asymmetry includes:

- Genetic or congenital malformations such as hemifacial microsomia and unilateral clefts of the lip and palate

- Environmental factors such as habits and trauma

- Functional deviations such as mandibular shifts as a result of tooth interferences are common

- Developmental, cause unknown. ${ }^{3}$

Dental asymmetries and a variety of functional deviations can be treated orthodontically. On the other hand, significant structural facial asymmetries are not easily amenable to orthodontic treatment. ${ }^{4}$ These problems may require orthopedic correction during the growth period and/or surgical management at a later point.

PAC has been considered as one of the most valuable diagnostic aid for asymmetry evaluation. Various methods ${ }^{2,5}$ have been used in literature to assess facial morphology. Theses analysis are important to find any frontal skeletal asymmetry. And to study the frontal visual treatment objectives as well as to evaluate improvements in facial or dental proportions

For the assessment of facial asymmetries, Grummons and Kappeyne Van De Coppello have developed a major analysis system. ${ }^{2}$ Asymmetry rather than determining actual inconsistencies was the prime purpose of GA to identify individual differences, and no normative data were presented in this system. Through comparison of the horizontal plane, mandibular morphology, and linear asymmetries measurements, the attention was to investigate the skeletal and dental components of asymmetry. ${ }^{6}$

Most studies of facial asymmetry have reported that the right hemiface is usually wider than the left; however, fewer studies have reported on the laterality of chin deviation, a subject that also remains controversial. ${ }^{1,2,4,6,7}$ Hence, the purpose of this study was to investigate the asymmetry of the face using GA in Saudi adult male subjects and investigate the difference in asymmetry with published data.

\section{MATERIALS AND METHODS}

\section{Ethical Consideration}

This research was approved by the Ethics Committee of CODS10/6/2016. The personal information of participants was anonymized before analysis and was kept confidential. 
- Study design: Retrospective study.

- Subjects: The present study included standard (PAC) of one hundred Saudi male adults. The average age was $25 \pm 4$ years. The PAC was selected on the basis of inclusion and exclusion criteria from the radiology archive.

- The inclusion criteria of the subjects consisted of, no previous orthodontic treatment, no craniofacial deformity, no skeletal abnormality or deformity or surgery, both parents and grandparents being Saudi without any interracial marriage. Exclusion criteria are blurred PAC X-ray, subjects with orthodontic treatment and craniofacial deformity, facial or esthetic surgery.

- Measurements: All PAC digital tracings were carried out by a single calibrated investigator. Before doing any measurements, examiner underwent intensive training and calibration. 3D-On-Demand software (Seoul, Korea) was used to perform digital analysis in a standard manner. GA does not formulate a normative data of variables measured, however, GA helps determine the skeletal and dental components of asymmetry in a wide range. In this study, the analyses employed according to the GA method 2 are shown in Figure 1 and details are presented in Table 1 . All of the measurements are related to the horizontal plane, mandibular morphology and linear asymmetries (Fig. 1) and Table 1).

\section{Statistical Analysis}

Statistical package for social sciences (SPSS) software version 20 (Chicago, IL, USA) was used for data analysis and the descriptive analysis was carried out.

\section{Error Analysis}

The reliability of the method was analyzed by the Dalhberg's formula on 20\% randomly selected PAC. Selected PAC radiographs were redigitized and remeasured to calculate the error in the method after an interval of 3 weeks.

\section{RESULTS}

Normality of distribution of the obtained data are tested by the Kolmogorov-Smirnov test. We found, all the data were normally distributed. Dahlberg's formula results to determine the method-error were not exceeding 0.59 $\mathrm{mm}$ for the linear variables, 0.89 degrees for the angular variables.

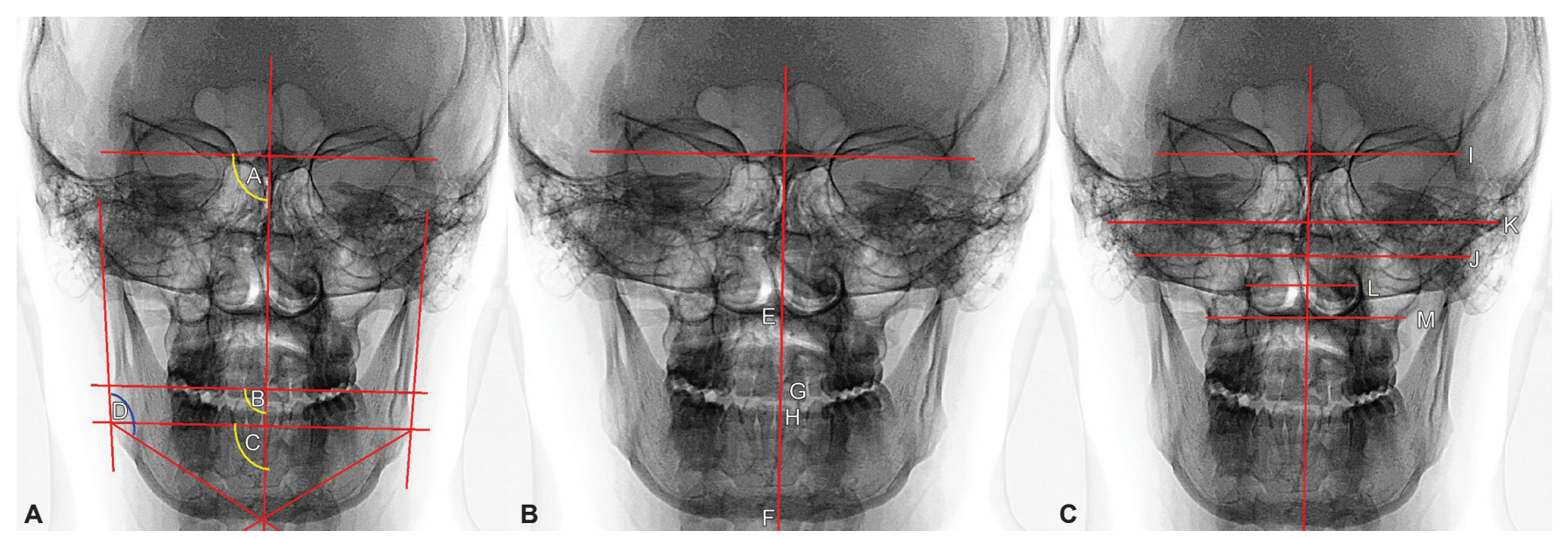

Figs 1A to C: Grummons analysis of PAC of an in the sample (details in Table 1)

Table 1: Details of the GA measurements using PAC

\begin{tabular}{ll}
\hline Variable & Description \\
\hline A. Z plane angle & Angle between Z plane and Cg-ANS line \\
B. Occlusal plane angle & Angle between occlusal plane and Cg-ANS line \\
C. Antegonial plane angle & Angle between antegonial plane and Cg-ANS line \\
D. Antegonial angle & Angle between mandibular ramus and mandibular body \\
E. & Anterior nasal spine deviation \\
F. & Mandibular deviation \\
G. & Maxillary dental midline deviation \\
H. & Mandibular midline deviation \\
I. & Frontozygomatic suture to X-line distance \\
J. & Condylion to X-line distance \\
K. & Zygoma distance \\
L. & Piriform aperture to X-line distance \\
M. & Maxilla buttress to X-line distance \\
\hline
\end{tabular}


Descriptive statistics of the GA for Saudi adult males were generated (Table 2); comparative statistics of mean and mean differences between the Saudi and Indian data were presented (Graph 1).

The mean, standard error, standard deviation, range measurement values representing GA angular and linear analysis are shown in Table 2.

\section{DISCUSSION}

The prime aim of this investigation was to evaluate the horizontal plane, mandibular morphology and linear asymmetries parameters based on GA for Saudi adult males. Minor and major asymmetry is an important factor to quantify asymmetry. For clinical and diagnostic purposes during growth and for adults and to

Table 2: Descriptive GA measurements of Saudi adult male using PAC

\begin{tabular}{|c|c|c|c|c|c|}
\hline Variable & Mean & $S E$ & $S D$ & Minimum & Maximum \\
\hline$Z$ plane angle & 89.03 & 0.08 & 0.84 & 87.70 & 90.50 \\
\hline Occlusal plane angle & 89.30 & 0.11 & 1.12 & 87.40 & 91.70 \\
\hline Antegonial plane angle & 89.92 & 0.12 & 1.17 & 87.40 & 91.50 \\
\hline Antegonial angle & 3.53 & 0.03 & 0.30 & 2.90 & 4.20 \\
\hline Anterior nasal spine deviation & 2.51 & 0.03 & 0.28 & 1.70 & 3.00 \\
\hline Mandibular deviation & 3.51 & 0.03 & 0.29 & 2.80 & 4.00 \\
\hline Max. dental midline deviation & 2.52 & 0.03 & 0.27 & 2.10 & 2.90 \\
\hline Mandibular midline deviation & 2.86 & 0.03 & 0.34 & 2.30 & 3.70 \\
\hline Frontozygomatic suture to X-line distance & 1.99 & 0.03 & 0.34 & 0.80 & 2.80 \\
\hline Condylion to X-line distance & 4.86 & 0.02 & 0.23 & 4.40 & 5.40 \\
\hline Zygoma distance & 4.84 & 0.03 & 0.29 & 4.20 & 5.50 \\
\hline Piriform aperture to X-line distance & 3.86 & 0.03 & 0.26 & 3.30 & 4.40 \\
\hline Max. buttress to X-line distance & 5.04 & 0.03 & 0.28 & 4.50 & 5.60 \\
\hline
\end{tabular}

A

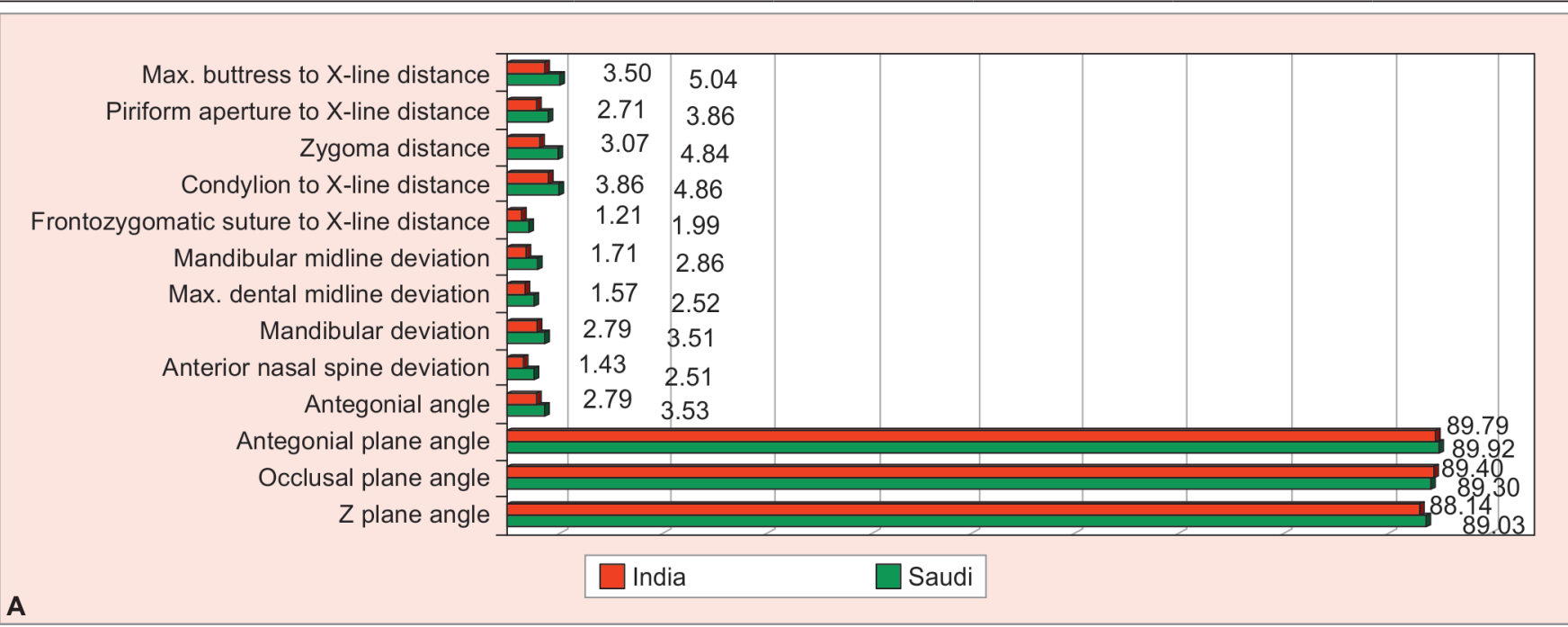

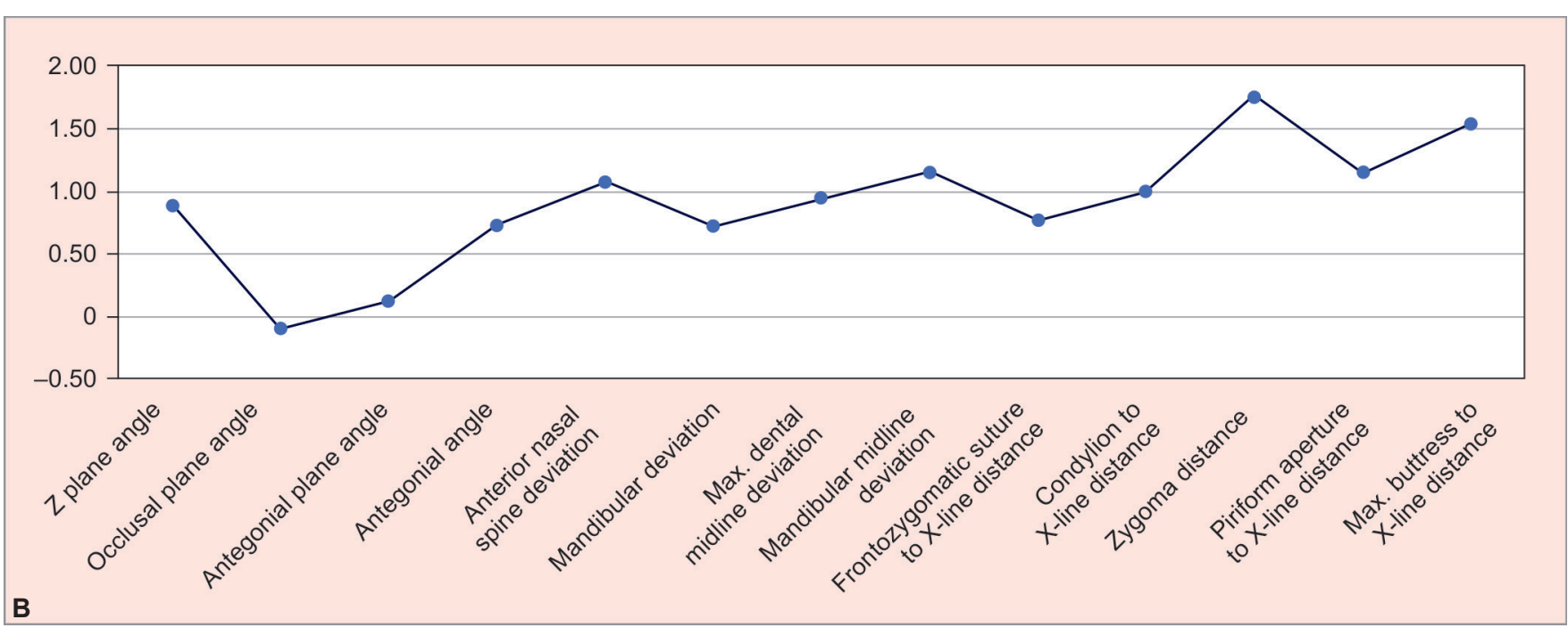

Graphs 1A and B: (A) Mean value comparison between Saudi and Indian (7) GA analysis of PAC;

(B) Mean differences between Saudi and Indian (7) GA analysis of PAC 
assess treatment results, quantification is indispensable to visualize the amount of asymmetry. For qualitative analysis of asymmetry, problems of skeletal, dental or soft tissue origin help in the diagnosis and treatment planning. ${ }^{1}$ Comprehensive analysis of facial asymmetry of the horizontal plane, mandibular morphology, and linear asymmetries parameters are important in different fields of medicine and dentistry, especially among specialists like plastic and reconstructive surgeons, oral and maxillofacial surgeons, orthodontists, and maxillafacial prosthodontists.

The spectrum of cephalometric analysis procedures have been used to determine the lateral skeletal dental and facial components of normal occlusion and malocclusion individuals of the different population and with varieties of analysis. ${ }^{8-42}$ For severe cases, the lateral cephalometric analysis used as an aid in orthodontic diagnosis, treatment planning, and follow-up. However, precise diagnosis of differences in a horizontal plane, mandibular morphology, and linear asymmetries parameters may also require a PAC estimation.

\section{Angular Measurement}

Four angular measurements for adult Saudi males on PAC were carried out. Two measurements are larger and two are quite similar to the PAC values of Indian adults with normal occlusion. ${ }^{7}$ Interestingly, both of the larger values are quite similar with the PAC values of Indian adults with class II subdivision malocclusion. ${ }^{7}$ These differences may depend on subject selection criteria. PAC of Indian subjects was selected based on dental model criteria, as well as, Saudi PAC are only from an adult male. These may be responsible for the disparities.

\section{Linear Measurement}

Four linear measurements of GA are related to the asymmetry of the lower third of the face. These are anterior nasal spine deviation, mandibular deviation, maxillary dental midline deviation, and mandibular midline deviation. The current study found asymmetries in all four measurements. These results coincide with the previously published researches on Brazilian ${ }^{43}$ and Indian ${ }^{7}$ PAC. Jabeen et al. ${ }^{7}$ found asymmetries in relation to normal occlusion group as well as in the class II subdivision group of malocclusion subjects. Their results are quite similar in both groups. Saudi adults showed even more disparities than the Indian normal and class II subdivision subjects group. ${ }^{7}$ These results also coincide with the Brazilian PAC results. ${ }^{43}$

\section{Linear Asymmetries}

All of the five variables of linear asymmetry values for Saudi adult male are greater than PAC values of Indian normal occlusion subjects. ${ }^{7}$ However, Indian class II subdivision malocclusion PAC values for the zygoma distance are even larger than the normal as well as Saudi adult male's data. Condylion to X-line distance data of Indian class II subdivision malocclusion subjects are quite similar to the Saudi adult male's data.

Many kinds of literature published regarding asymmetries using PAC. ${ }^{4,7,44}$ They have shown PAC measurements are different from those in normal occlusion and with the malocclusion groups. ${ }^{4,7,43,44}$ Asymmetries are common in normal and malocclusion group. Our results also found similarities with previously published literature. ${ }^{4,43}$ Major limitations of this study are comparison with the malocclusion group and with the female group was not possible, as all the subjects were selected based on good facial harmony rather than malocclusion grouping and all of the subjects are limited to the male gender. These results are from the subjects of the northern region of Saudi Arabia. Other areas subjects should include to see the possible disparities as well as in different dental and skeletal malocclusion groups.

\section{CONCLUSION}

Based on results following conclusion can be drawn:

- The present data demonstrate GA of means, standard error, standard deviation, and ranges of commonly used PAC parameters for a large, representative sample of adult Saudi male.

- Facial asymmetry was revealed in Saudi adult male based on PAC of GA.

- The findings are very much different with Indian normal occlusion data were found.

\section{REFERENCES}

1. Shah SM, Joshi MR. An assessment of asymmetry in the normal craniofacial complex. Angle Orthod. 1978;48:141-147.

2. Grummons DC, Kappeyne Van De Coppello MA. A frontal asymmetry analysis. Journal of Clinical Orthodontics. 1987;21:448-465.

3. Cheong Y-W. Facial Asymmetry: Etiology, Evaluation, and Management. Chang Gung Med J. 2011;34:341-351

4. O'Byrn BL. An evaluation of mandibular asymmetry in adults with unilateral posterior cross bite. Am J Orthod Dentofacial Orthop. 1995;107:394-400.

5. Grayson BH, McCarthy JG, Bookstein F. Analysis of craniofacial asymmetry by multiple cephalometry. American Journal of Orthodontics. 1983;84:217-224.

6. Letzer GM, Kromaj JH. A posterioanterior cephalometric evaluation of craiofacial asymmetry. Angle Orthod. 1967;37: 205-211.

7. Jabeen N, Manohar MR, Shivprakash G, Naik P. Evaluation of Asymmetries associated with Class II subdivision malocclusions and Normal occlusion. IOSR Journal of Dental and Medical Sciences (IOSR-JDMS). 2014;13(1):07-14.

8. Alam MK, Basri R, Purmal K, Sikder MA, Saifuddin M, Iida J. Cephalometric evaluation for Bangladeshi adult by 
Steiner analysis. International Medical Journal. 2012;19: 262-265.

9. Alam MK, Basri R, Kathiravan P, Sikder MA, Saifuddin M, Iida J. Cephalometric evaluation for Bangladeshi adult by Down's analysis. International Medical Journal, 2012;19:258-261.

10. Alam MK, Basri R, Purmal K, Sikder MA, Saifuddin M, Iida J. A soft tissue cephalometric analysis for Bangladeshi adult using Holdway's analysis. International Medical Journal. 2012;19:333-336.

11. Alam MK, Basri R, Purmal K, Sikder MA, Saifuddin M, Iida J. Determining cephalometric norms for Bangladeshi adults using Bjork-Jarabak's analysis. International Medical Journal. 2012;19:329-332

12. Alam MK, Basri R, Purmal K, Sikder MA, Saifuddin M, Iida J. Cephalometric norm study in a Bangladeshi population using Mcnamara analysis. International Medical Journal. 2013;20:84-86.

13. Alam MK, Basri R, Purmal K, Sikder MA, Saifuddin M, Iida J. Cephalometric norms in Bangladeshi adults using Harvold's analysis. International Medical Journal. 2013;20:92-94.

14. Alam MK, Basri R, Purmal K, Sikder MA, Saifuddin M, Iida J. Craniofacial morphology of Bangladeshi adult using Tweed's and Wit's analysis. International Medical Journal. 2013;20:197-200.

15. Purmal K, Alam MK, Zam Z, Mohammad N. Cephalometric norms of malaysian adult chinese. International Medical Journal. 2013;20:87-91.

16. Purmal K, Alam MK, Zam Z, Mohammad N. Cephalometric norms of malaysian adult indian International Medical Journal. 2013;20:192-196.

17. Purmal K, Alam MK, Zam Z, Mohammad N. Cephalometric comparison of skeletal, dental, soft tissue, nose and chin prominence between Malaysian Indian and Malaysian Chinese. International Medical Journal. 2013;20:335-341.

18. Alam MK, Basri R, Purmal K, Rahman SA, Shaari R, Haq ME. Cephalometric for orthognathic surgery (COGS) for Bangladeshi population. International Medical Journal. 2013;20:345348.

19. Alam MK, Basri R, Purmal K, Sikder MA, Saifuddin M, Iida J. Cephalometric lip morphology in Bangladeshi population. International Medical Journal. 2013;20:201-203.

20. Alam MK, Qamruddin I, Muraoka R, Nakano K, Okafuji N. Validity of W Angle and YEN Angle in a Sample from Pakistani and Bangladeshi Populations. Journal of Hard Tissue Biology. 2014;23:351-356.

21. Talib MA, Abdul Aziz NS, Alam MK, Basri R, Purmal K, Rahman SA. Linear and Angular Cephalometric Measurement of Lip Morphology among Malaysian Malay. International Medical Journal. 2014;21:41-44.

22. Abdul Aziz NS, Talib MA, Alam MK, Basri R, Purmal K, Rahman SA. Linear and Angular Cephalometric Lip Morphology in Malaysian Chinese Population. International Medical Journal. 2014;20(1):41-48.

23. Alam MK, Talib MA, Abdul Aziz NS, Basri R, Purmal K, Rahman SA. Comparison of Linear and Angular Cephalometric Lip Morphology in Malaysian Malay and Malaysian Chinese Population. International Medical Journal. 2014;21(2):177-180.

24. Bahaa O, Khamis MF, Alam MK, Mokhtar N. Comparative Cephalometric Analysis between Class III and Class I Malocclusion of Malay Females. International Medical Journal. 2014;21(3):283-286.
25. Alam MK, Nowrin SA, Shahid F, Haque S, Basri R. Cephalometric Characteristics of Bangladeshi adults with Class II Malocclusion. International Research Journal of Medical Sciences. 2014;2(11):10-14.

26. Alam MK, Nowrin SA, Yusof A, Ahmad B. Changes of lip morphology in relation to different skeletal index: in Malaysian Malay and Malaysian Chinese population. International Journal of Pharma and Bio Sciences. 2015;6(2):770-778.

27. Shokor FFBA, Rahman WSB, Alam MK. Craniofacial morphology with genetic influence of $\mathrm{ABO}$ blood group in Malaysian orthodontic patients. International Journal of Pharma and Bio Sciences. 2015;6(4):412-418.

28. Qamaruddin I, Alam MK. Cephalometry: is it just an orthodontic record? Bangladesh Journal of Medical Science. 2015;14(4):313-315.

29. Alam MK, Qamruddin I, Basri R, Begum S, Sikder MA, Saifuddin M. Assessment of Sagittal Discrepancies in Bangladeshi Adults: Latest and Old Approaches. International Medical Journal. 2016;23(4):411-413.

30. Alam MK, Qamruddin I, Basri R, Harun KMAL, Mat Arifin MNA, Kamarazaman KB. Assessment of Sagittal Discrepancies in Malay Population: Latest and Old Approaches. International Medical Journal. 2016;23(4):414-416.

31. Alam MK, Qamruddin I, Basri R, Harun KMAL, Mat Arifin MNA, Kamarazaman KB. Cephalometric Comparison of Sagittal Analyses between Malay and Bangladeshi Population: Old and Recent Approach. International Medical Journal. 2016;23(4):417-419.

32. Alam MK, Qamruddin I, Basri R, Harun KMAL, Mat Arifin MNA, Kamarazaman KB. Cephalometric Comparison of Sagittal Analyses between Malay and Malaysian Chinese: Old and Recent Approach. International Medical Journal. 2016;23(4):420-423.

33. Alam MK, Qamruddin I, Siddiki MN, Basri R, Harun KMAL, Mat Arifin MNA, Kamarazaman KB. Assessment of Sagittal Discrepancies between Malay and Pakistani Population: Latest and Old Approaches. International Medical Journal. 2016;23(4): 424-427.

34. Alam MK, Qamruddin I, Basri R, Harun KMAL, Mat Arifin MNA, Kamarazaman KB. Assessment of Sagittal Discrepancies in Malaysian Chinese Population: Latest and Old Approaches. International Medical Journal. 2016;23(4): 428-430.

35. Alam MK, Qamruddin I, Basri R, Harun KMAL, Mat Arifin MNA, Kamarazaman KB. Assessment of Sagittal Discrepancies between Malaysian Chinese and Bangladeshi Population: Latest and Old Approaches. International Medical Journal. 2016;23(4):431-433.

36. Alam MK, Qamruddin I, Basri R, Harun KMAL, Mat Arifin MNA, Kamarazaman KB. Assessment of Sagittal Discrepancies between Malaysian Chinese and Pakistani Population: Latest and Old Approaches. International Medical Journal. 2016;23(4):434-437.

37. Alam MK, Nowrin SA, Shahid F, Basri R, Qamaruddin I, Rahman NA. Determining Cephalometric Characteristics of Bangladeshi Adults with Class III Malocclusion. International Medical Journal. 2016;23(5):572-575.

38. Alam MK, Iberahim NFB, Mukai A, Imanishi T, Yusa T, Roszali NHB, Haque S, Basri R. Sagittal and Vertical OcclusalCephalometric Analyses of Pancherz among Malaysian Malays and Malaysian Chinese. Journal of Hard Tissue Biology. 2016;25[4]:403-412. 
39. Malik H, Afridi SK, Kamran MA, Mahroof V, Alam MK, Qamruddin I. A Cephalometric Analysis for Pakistani Adults Using Jarabak Bjork's Analysis. International Medical Journal. 2017;24(1):128-131.

40. Khan F, Mahroof V, Kamran MA, Shafiqullah, Alam MK, Qamruddin I. Cephalometric Lip Morphology in a Sample from Pakistani Population. International Medical Journal. 2017;24(1):140-143.

41. Khan SA, Mohammad PA, Tariq J, Khan F, Khursheed T, Jehan S, Alam MK, Qamruddin I. Cephalometric Study of Pakistani Population Using McNamara Analysis. International Medical Journal. 2017;24(1):144-146.
42. Shafi AM, Khan FNA, Khan AG, Nadeem M, Khursheed T, Jehan S, Qamaruddin I, Alam MK. A Soft Tissue Cephalometric Analysis for Pakistani Adult Using Holdaway's Analysis. International Medical Journal. 2018;25(1):51-53.

43. Azevedo AR1, Janson G, Henriques JF, Freitas MR. Evaluation of asymmetries between subjects with Class II subdivision and apparent facial asymmetry and those with normal occlusion. Am J OrthodDentofacialOrthop. 2006 Mar;129(3): 376-383.

44. Rose JM, Sadowsky C, BeGole EA, Moles R. Mandibular skeletal and dental asymmetry in Class II Subdivision malocclusions. American Journal of Orthodontics. 1994;105(5):489-495. 